28. Heinild S, Sondergaard T, Tudvad F. Bone marrow infusion in childhood : Experiences from a thousand infusion. $J P e$ diatr $1947 ; 30: 400-412$.

29. Walden $\mathrm{L}$. On injuries of bone and bone marrow after intraosseous injection : an experimental investigation. Acta Chir
Scand 1947; $96:$ 152-162.

30. Brickman, KR, Rega P, Koltz M et al. Analysis of growth plate abnormalities following intraosseous infusion through the proximal tibial epiphysis in pigs. Ann Emerg Med 1988; $17: 121-123$

\title{
GROWTH OF INDIAN CHILDREN vS WHITE CHILDREN
}

The growth of children in India differs from that of white children. Among upper-class Indian children, growth is approximately 'normal' until around puberty; it then slows down and ceases at an age earlier than in white children. This pattern is also secn in Indian immigrants in other parts of the world-Southern Africa, West Indies, and the UK. Thus in the East End of London (UK), Indian boys aged 17 years are on average $7 \mathrm{~cm}$ shorter and 13 $\mathrm{kg}$ lighter than British boys.

To learn more of the bearing of genetic, socio-economic and other factors on the growth of Indian peoplc, heights and wcight were measured of 4,594 pupils who attended schools representative of upper, intermediate, and lower socio-economic classes. Upper-class children were significantly bigger at all ages than children in the lower or poor classes, but differences tended to lessen by the age of 17 years. In the affluent group, under the 5th percentile of the National Centre for Health Statistics (NCHS) reference values, height for age ranged from $4.7 \%$ to $22.0 \%$ in boys, and from $5.08 \%$ to $20.7 \%$ in girls; weight for age ranged from $20.3 \%$ to $45.0 \%$ in boys and from $9.3 \%$ to $37.3 \%$ in girls. At full growth at 17 years, mean height and weight were significantly less, roughly by $7 \mathrm{~cm}$ and $10 \mathrm{~kg}$ respectively, in the affluent group than in white children in NCHS reference data. The lower attainment of ultimatc height in Indian children appears to be largely genetically determined and not due to simple dictary insufficiency. 